\title{
Maestros de la construcción. Protagonistas subalternos del proceso de reconstrucción de los cerros de Valparaíso en Chile $^{1}$
}

\author{
Master Builders. Subaltern Protagonists in the \\ Reconstruction Process of the Valparaiso Hills in Chile
}

Héctor Claudio Rivera-Vergara ${ }^{2}$

Profesor adjunto, Escuela de Trabajo Social, Facultad de Ciencias Sociales y Comunicaciones, Universidad Santo Tomás, Santiago, Chile.

hectorriveravergara@gmail.com

ORCID: http://orcid.org/0000-0002-2319-2899

\section{Luis Alfredo Campos-Medina ${ }^{3}$}

Profesor asistente del Instituto de la Vivienda de la Facultad de Arquitectura y Urbanismo, Universidad de Chile, Santiago, Chile. luiscampos@uchilefau.cl

ORCID: http://orcid.org/0000-0002-5157-4974

Recibido: 29-05-2018

Aprobado: 20-03-2019

1 El presente artículo se enmarca dentro del Proyecto FONDECYT 11140356, "La dimensión espacial de la experiencia de sufrir en el Chile contemporáneo. Los casos de la enfermedad y la catástrofe”. Financiado por La Comisión Nacional de Investigación Científica y Tecnológica -CONICYT- Ministerio de Educación, Gobierno de Chile.

2 Maestría en Sociología.

3 Doctor en Sociología. 


\section{Resumen}

El artículo indaga de qué manera los maestros de la construcción como protagonistas subalternos actúan, perciben y explican el proceso de reconstrucción de los cerros de Valparaíso en Chile. El interés de escuchar al maestro de la construcción en su condición de sujeto subalterno -mediante una metodología de carácter cualitativo, empleando seis entrevistas focalizadas a maestros de la construcción, además de veinte entrevistas a habitantes afectados por el incendio, y un proceso de observación etnográfica, en terreno, realizado durante catorce meses-, radica en analizar los significados de ciudadanía, hegemonía y espacios de resistencia en el proceso de reconstrucción. En este sentido, los resultados indican que los mecanismos de solidaridad, con el otro que sufre, se presentan como una resistencia a la hegemonía política-económica, basada en una consciencia individual y colectiva, tendiente a conseguir el bienestar y el bien común.

Palabras clave: reconstrucción; maestros de la construcción; subalternidad; resistencia; solidaridad.

\section{Abstract}

The article inquires in the way master builders as subaltern protagonists act, perceive and explain the reconstruction process of the Valparaiso hills in Chile. The interest of listening to the master builder in his condition as a secondary subject (using a qualitative character methodology, six interviews focused on the master builders, besides twenty interviews to inhabitants affected by the fire, and a process of ethnographic observation in the area for fourteen months), lies in analyzing the meanings of citizenship, hegemony and areas of resistance in the process of reconstruction. In this sense, the results indicate that the mechanisms of solidarity among those who suffer, appear as a resistance to the political-economic hegemony which is based on an individual conscience, working to obtain the well-being and the common good.

Keywords: Reconstruction; Building Masters; Subalternity; Resistance; Solidarity.

¿Cómo citar este artículo? / How to quote this article?

Rivera-Vergara, H. C. y Campos-Medina, L. A. (2019). Maestros de la construcción. Protagonistas subalternos del proceso de reconstrucción de los cerros de Valparaíso en Chile. Sociedad y economía, (37), 114-130. https://doi.org/10.25100/sye.voi37.7825 


\section{Introducción}

El presente artículo busca comprender cómo los maestros de la construcción en su condición de sujeto subalterno actúan, perciben y explican los procesos de reconstrucción de los cerros de Valparaíso en Chile, desde un análisis de los significados de ciudadanía, hegemonía y espacios de resistencia en el proceso de reconstrucción. Cabe señalar que, al referirnos a los maestros de la construcción, lo hacemos en referencia al trabajador-obrero formal o informal, que posee conocimientos y experiencia en labores de albañilería, que ejerce funciones laborales en construcción, transformaciones, y reparaciones de viviendas y edificaciones, siendo un subordinado de los arquitectos e ingenieros en construcción.

Al realizar una breve contextualización de los programas de reconstrucción de Valparaíso, se debe señalar que el incendio -ocurrido entre el 12 y 16 de abril del 2014- ha sido uno de los eventos más catastróficos del último tiempo en Chile. Según cifras del Ministerio del Interior y Seguridad Pública (2014), afectó un área de 1.090 hectáreas, comprendidas desde el sector de La Pólvora, el Vergel, hasta los cerros Mariposas, Monjas, La Cruz, El Litre, Las Cañas, Merced, La Virgen, Santa Elena, Ramaditas y Rocuant; con 10.292 personas damnificadas, 500 heridas, 15 víctimas fatales y 2.975 viviendas destruidas.

Ante esta tragedia, el Estado de Chile implementa el "Plan de inversiones, reconstrucción y rehabilitación urbana. Valparaíso 2014-2021 aprobado el 17 de junio del 2014 por la Comisión Interministerial Ciudad, Vivienda y Territorio ${ }^{4}$ con el objetivo de alcanzar, en el breve plazo, la normalización de las vidas de los damnificados. Para ello se planteó una intervención en tres fases: emergencia, transición y reconstrucción.

A. Emergencia: orientado a la atención de los damnificados en sus necesidades básicas, dotán-

4 La Comisión Interministerial Ciudad, Vivienda y Territorio está compuesta por el Ministerio de Obras Públicas, Ministerio de Transporte y Telecomunicaciones, Ministerio del Interior y Seguridad Pública, y la Subsecretaría de Desarrollo Regional y Administrativo (SUBDERE). dolos de albergues, comida y vestuario. Además del retiro de escombros y limpieza de las zonas afectadas, velando por la seguridad y el orden público.

B. Transición: centrada en la implementación de soluciones habitacionales transitorias, mediante subsidios de arriendo, acogida e instalación de viviendas prefabricadas de emergencia, a la espera de las soluciones definitivas. Sumado a beneficios de manutención económica de cada familiapor un periodo de tres meses renovables -según evaluación caso a caso- a seis meses adicionales.

C. Reconstrucción: planificación tendiente a recuperar el tejido y el patrimonio social mediante la triada ciudad barrio vivienda, permitiendo la construcción de barrios más integrados, seguros y de mayor calidad para la población damnificada.

Estas tres fases tenían, como objetivo, la articulación y participación de la ciudadanía damnificada por el incendio para una "intervención a escala ciudad," a través de los Consejos de Desarrollo Vecinal para el diseño, implementación y evaluación de los programas de Recuperación de Barrios, en coordinación con el Comité de Ministros de Ciudad y Territorio, la Intendencia Regional de Valparaíso y el Delegado Presidencial para la Reconstrucción.

En términos concretos, la intervención a escala ciudad se dividió en dos ejes programáticos. El primer eje se abocó a las obras de infraestructura y seguridad de la ciudad de Valparaíso, con una inversión en dólares de US\$158.225.000, consistente en:

A. El mejoramiento de la conectividad y accesibilidad a los sectores altos de la ciudad.

B. El mejoramiento de la seguridad y las condiciones ambientales, a través de un estudio integral de las quebradas de los cerros y modificación de las normativas urbanas de construcción de viviendas.

C. La reforestación de las zonas afectadas, inversiones en obras hidráulicas e implementación 
de redes de estanques de agua. Sumado a la constitución de la unidad operativa de control de las emergencias -compuesta por la ONEMI 5 , Bomberos y CONAF ${ }^{6}$ - encargada de diseñar y ejecutar los programas de seguridad y respuesta ante incendios.

D. El mejoramiento de la movilidad y accesibilidad urbana, mediante un circuito integrado de transporte público.

El segundo eje se concentró en la reconstrucción de las viviendas, mediante un plan de inversión a cargo del Ministerio de Vivienda y Urbanismo que establecía cuatro modalidades de reconstrucción, con un estimado de 2000 viviendas y una inversión, en dólares, de US\$ 29.871.310 consistente en:

A. Subsidios en zonas seguras o "aseguradas" para construir, instalar vivienda emergencia o autoconstruir (incluida asistencia e inspección técnica).

B. Subsidios para adquirir viviendas en otros lugares.

C. Subsidios para construcción en nuevos terrenos.

D. Subsidios para reparar vivienda.

Para los fines de este artículo nos centraremos en el segundo eje, a través de las actuaciones, percepciones y explicaciones que entregan los maestros de la construcción al proceso de reconstrucción. Nos posicionamos desde una teoría de la subalternidad, que se presenta enmarcada en disposiciones eminentemente mercantiles, basadas en una neoliberalización extrema con sucesivas subcontrataciones de la

5 Oficina Nacional de Emergencias Dependiente del Ministerio del Interior y Seguridad Pública (República de Chile). Encargada de prevenir o solucionar problemáticas de emergencias naturales y planificar, coordinar y ejecutar las acciones destinadas a prevenir o solucionar los problemas derivados de catástrofes.

6 La Corporación Nacional Forestal es un organismo dependiente del Ministerio de Agricultura del Estado de Chile, mandatado a supervisar la política pública forestal, mediante la administración de sus parques, reservas y áreas silvestres. Además de prevenir y combatir incendios forestales. mano de obra, un aumento artificial de los precios de reconstrucción y atrasos en la entrega de las obras, situación que denota los principios de un patrón de acumulación capitalista, que se centra en la utilidad económica en desmedro de los derechos de los ciudadanos damnificados.

En efecto, el proceso de reconstrucción ha presentado deficiencias en la planificación y gestión de los recursos, perjudicando directamente la calidad de vida de los damnificados, quienes han visto cómo los anhelos y esperanzas de habitar sus viviendas reconstruidas han sido truncados por empresas constructoras que no cuentan con las mínimas capacidades administrativas y técnicas para dar cumplimiento a los plazos establecidos de entrega. Sustentamos este argumento con observaciones etnográficas realizadas por más de un año, sumado a variadas entrevistas a los habitantes de los cerros afectados, pero esencialmente al testimonio de los "maestros de la construcción", los cuales han sido testigos y, de algún modo, también víctimas de la ineficiente gestión de las empresas constructoras.

Desde el punto de vista laboral, los maestros de la construcción pueden ser considerados como trabajadores por cuenta propia, quienes -de acuerdo a la Organización Internacional del Trabajo- son "aquellos trabajadores que, trabajando por su cuenta o con uno o más socios, socios no son necesariamente miembros de la misma familia u hogar, tienen el tipo de empleo definido como 'empleo independiente' y no han contratado a ningún 'empleado' de manera continua para que trabaje para ellos durante el período de referencia. Cabe notar que durante el período de referencia los miembros de este grupo pueden haber contratado 'empleados', siempre y cuando lo hagan de manera no continua" (OIT, 2003, p. 73).

Tal condición, redunda en que hacen parte del sector informal, caracterizado por pequeñas unidades económicas estructuradas en economías de subsistencia y estrategias de sobrevivencia; las cuales son administradas generalmente por personas sin educación superior, dedicadas al área de la producción y el servicio, que no cum- 
plen en general con las normas legales que regulan el mercado del trabajo, además de tener baja productividad e inestabilidad económica.

En síntesis, estas características son las que nos llevan a pensar que los maestros de la construcción pueden ser concebidos como un sujeto subalterno, que de acuerdo a los planteamientos de Gramsci (1981), es definido como "un sujeto que poseía una condición de marginado ya sea por su clase, casta, género, creencias, etc." (p. 24). Particulares características que lo subordinan al poder de las ideologías y la economía política, otorgándole una relación histórica predeterminada por los medios de producción, estableciéndose como un sujeto en negación, dada su condición de sumisión, subordinación o simplemente por estar debajo de otro con más poder económico-político.

Así, entonces, es relevante poder escuchar la perspectiva de los maestros de la construcción, ya que ocupan una posición esencial en los procesos de implementación y ejecución de los programas de reconstrucción, puesto que son el eslabón encargado de reconstruir las edificaciones destruidas. Instancia en la que interactúan con las víctimas de la tragedia, autoridades y las empresas constructoras, que les permite configurar una visión particular, muchas veces acompañada de la falta de respeto de sus derechos laborales y de una política pública que incentiva las formas de acumulación capitalista.

Por ello, la metodología que utilizamos es de carácter cualitativo, empleando seis entrevistas focalizadas a maestros de la construcción, entendidas como una conversación entre un entrevistador y un entrevistado, con el propósito de obtener información exigida en los objetivos de una investigación (Briones, 1999; Valles, 1993). A esto se añaden veinte entrevistas a habitantes afectados por el incendio y un proceso de observación etnográfica en terreno, realizado durante catorce meses. Todo ello nos ha permitido conformar un análisis inductivo de la información generada, orientado a "descubrir las estructuras o sistemas dinámicos que dan forma a los fenómenos observados" (Martínez, 2002, p. 29). Accediendo a comprender de qué manera los maestros de la cons- trucción, en su rol activo en la reconstrucción de las viviendas siniestradas, actúan, perciben y explican el proceso de reconstrucción.

Por otro lado, hemos definido dos categorías de análisis, estructuradas desde las afirmaciones, evaluaciones y percepciones de los maestros de la construcción en la relación Estado-Mercado y la relación Habitantes-Damnificados. Además, desde las categorías antes mencionadas, desarrollamos una reflexión sobre los alcances y limitaciones en la constitución de mecanismos de solidaridad, con el otro que sufre, desde la visión de los maestros de la construcción y los damnificados por el incendio.

De este modo, el artículo se compone de tres apartados. El primero realiza una breve reseña de la teoría de la subalternidad, con la finalidad de establecer cuál de las perspectivas presentadas es la que nos permite constituir un adecuado ensamblaje teórico-contextual, para el abordaje del objetivo de este estudio. El segundo, efectúa el análisis de los datos recolectados desde las categorías: relación Estado-Mercado y relación Habitantes-Damnificados, ambas con sus respectivas subcategorías de análisis. El tercer apartado presenta una reflexión de los alcances y limitaciones de los mecanismos de solidaridad con el otro que sufre, en relación a los resultados del análisis. Finalmente, se exponen las conclusiones del estudio.

\section{La visión subalterna del proceso de reconstrucción. Una breve reseña}

La génesis teórica de lo que se entiende por sujeto subalterno, según Szurmuk y Mckee (2009) se puede entender en función de cuatro genealogías de influencia:

A. La ensayista: surge a finales del siglo XIX, en Latinoamérica. En ella se abordan los cambios sociales, políticos y económicos después del periodo colonial, relatando la opresión a que fue sometido el proletariado campesino y urbano por parte de los poderes oligárquicos y del Estado (Sarmiento, Martí, Rama, Polar). 
B. La teoría crítica: desarrollada, desde el siglo XX, por las Escuelas de Frankfurt (Horkheimer, Adorno, Benjamín, Marcuse, Habermas, etc.) y Birmingham (Thompson, Hoggart, Hall, Williams, etc.), además del posestructuralismo francés (Barthes, Deleuze, Lacan, Foucault, etc.), abordando la racionalidad instrumental, en la esfera de lo político-económico, como mecanismo de dominación sociocultural.

C. La crisis de la subjetividad: desarrollada, desde el siglo XX, a partir de la perspectiva marxista de Gramsci, realizando estudios de subalternidad desde la totalidad hegemónica de lo político-económico no europeo, centrándose en las realidades de los marginados de los continentes de Asia, América y África (Guha, Ranajit, Berveley, etc.).

D. Estudios culturales en Estados Unidos: desarrollados desde el siglo XX, enfocados en las investigaciones de subalternidad de las minorías de género como homosexualidad, lesbianismo, transexualidad, y el racismo, como los afroamericanismos, asiamericanismos, entre otros (Szurmuk, Yudice, During, Striphas, etc.).

De lo antes expuesto, nos interesa abordar la subalternidad del maestro de la construcción desde los lineamientos de la teoría crítica y la crisis de la subjetividad. Esto en función de un contexto histórico de profundización del neoliberalismo económico, que ha instituido un prisma hegemónico global y ha transformado al mercado en el principal agente operador en la constitución y reproducción de lo social. Se impone, así, una razón técnica que interviene las relaciones sociales, ajustando las actividades a los parámetros economicistas, "evaluándolas por una maximización de las inversiones y rendimientos, homogenizando las conductas individuales y restringiendo las diferencias" (Weber, 2004, p. 25).

Esto repercute en la instauración de narrativas de ciudadanos-sujetos subalternos, determinados por la dominación de un poder políticoeconómico hegemónico y, con ello, la negación de su condición emancipadora y el vacío de su subjetividad sociopolítica (Guha \& Spivak, 1988;
Guha, 1996; Glissant, 1989; Greenblatt, 1992), en la articulación Estado- Sociedad Civil (Gramsci, 1981).

En efecto, la hegemonía del poder político-económico produce una individualización que impide la autonomía de los procesos socioculturales y de subjetivación política, debido a la ruptura con las interrelaciones e interdependencias de sus ejes tradicionales. Con lo cual debe someterse a las constricciones del mercado y el consumo para su integración y cohesión social, institucionalizando tanto su mundo público como privado.

La amplia socialización de valores individualistas, narcisistas, en el seno de la sociedad de consumo y el impacto desmovilizador de la crisis, desplazan el centro de atención ideológico del ámbito público al privado y de la acción colectiva al espacio de la privacidad. Es el pasaje de la centralidad que tenía la figura del trabajador a la del consumidor (García, 1989, p. 62), "provocando una subalternidad unificada por la dominación del poder político-económico desde las teorías de Oriente y Occidente" (Glissant, 1989, p. 32).

La racionalidad técnica se muestra con un poder incontrarrestable sobre la sociedad, estableciendo una dominación desde la esfera económica, que ha estructurado un control de la consciencia individual. Parafraseando a Horkheimer (2002), la razón objetiva se ha transformado en una razón subjetiva o instrumental, en la cual, la acción individual que perseguía la justicia social de la comunidad y, a su vez, su propia felicidad, ha sido transformada en una acción que prioriza la búsqueda de la funcionalidad y el utilitarismo. Esto con el objetivo de alcanzar fines prácticos que otorguen satisfacciones a las necesidades inmediatas. Desarrollando una consciencia que se adapta a los procesos de alienación capitalista e imponen una verdad única dada por los intereses de la técnica, deshumanizando sus prácticas humanas de espiritualidad y sentimientos.

Consideramos que la justificación del relato del maestro de la construcción, en su experiencia con los procesos de reconstrucción, se basa 
en una "descolonización del saber para la conformación de una ecología del saber" (SousaSantos, 2010, p. 29). Ecología del saber centrada en realidades concretas, que han sido evidenciadas por el maestro de la construcción -en su condición de subordinado a la hegemonía económicopolítica- experimentando las contradicciones en la constitución de su subjetivación política, "ya no sólo en la relación de los modos de producción, sino también desde la transculturización y el sincretismo de un ciudadano multicultural mediado y afectado por un poder hegemónico de dominación" (Guha \& Spivak, 1988, p. 42).

De este modo, ya no basta con identificar al sujeto, sino que se debe ubicar, también, el lugar o espacio geopolítico y sociopolítico subalterno en donde se desarrolla esa subalternidad; basada en una determinación histórica, económica y cultural, que impone las condiciones y límites de validación e intervención del sujeto en sociedad como formas de resistencia (Foucault, 1977; Delleuze, 1998; Guattari, 1973), para sus posibilidades emancipadoras.

Por ello, justificamos escuchar el relato del maestro de la construcción, estimando que es la mejor forma de evaluar las posibilidades de emancipación desde una realidad concreta, mediante la descripción de lo que lo afecta a él, como también, a los miembros de su misma clase, en condición de damnificados por el incendio. Asimismo, buscamos comprender de qué manera los modos de producción hegemónicos y las subordinaciones estatales, en la dimensión cultural, conforman realidades y verdades simbólicas estructuralmente narradas en conformidad con los fines del poder estatal, en donde la subalternidad se presenta "negada de comunicación, produciendo un vacío, el lado oscuro y demostrando lo bestial que puede ser el humano en una modernidad occidental" (Spivak, 1988; Glissant, 1989; Greenblatt, 1992; Mignolo, 1995; Hume, 1986).

En este sentido, y siguiendo los lineamientos de Spivak (1988), proponemos desde una modernidad no occidental, ubicada en un país como Chile, que un sujeto subalterno puede ser escuchado a través de sus silencios, palabras y testimonios, en un ejercicio de recepción e interpretación que no puede limitarse a las lógicas de producción, sino que también debe referirse a sus necesidades objetivas y subjetivas; manifiestas en resistencia a la dominación de las convergencias culturales existentes, descubriendo sus sensibilidades en su instituida dominación desde "la solidaridad con el otro, para constitución de una crítica" (Guha, 1996, p. 9). En otras palabras, escuchar el discurso del sujeto subalterno también en sus posibles resistencias, en contra de la hegemonía estatal (Foucault, 1977; Delleuze y Guattar, 1972; Guattari, 1973), en una "transgresión del lugar asignado ejerciendo su poder epistemológico y reconociendo su agencia" (Guha, 1996, p. 4), para alcanzar sus objetivos de reivindicación política.

En definitiva, escuchar al maestro de la construcción -en su condición de sujeto subalterno del proceso de reconstrucción de las viviendas de Valparaíso- nos dará la oportunidad de analizar los significados de ciudadanía, hegemonía, sociedad y los espacios públicos de resistencias, etc. Esto con el fin de plantear "procesos de reconversión" (García, 1989, p. 4), entendidos como una constante resistencia y crítica a la cultura imperante, basada en una disciplina y normalización institucionalizada mediante las hegemonías y dominios de una élite económico-política que no permite mecanismos de igualdad y posibilidades de desarrollo con el objetivo de determinar: ¿cómo los mecanismos de dominación han configurado las relaciones de solidaridad con el otro que sufre? Asimismo, entregándonos la oportunidad de diferenciar entre una falsa o verdadera consciencia de clase (Lukács, 1970), enmarcado en su experiencia en el proceso de reconstrucción.

\section{Análisis de los datos: enlace investigativo-mundo experiencial}

En el apartado pretendemos observar los mecanismos de resistencia que presenta el maestro de la construcción, mediante su relato subalterno, que puede revelar un proceso de subjetivación política. Entendido como un proceso de formación de sí con el otro, que no alude a la 
búsqueda de la naturaleza interna negada por la sociedad, sino que es una construcción histórica en relación con otro (Angelcos, 2008), dotado de procesos de desclasificación y desidentificación, en el cual el sujeto niega lo que es, y, a la vez, interroga sobre las condiciones de posibilidad de su constitución mediante la resistencia y crítica a la hegemonía económica, política y social imperante.

\subsection{Relación Estado-Mercado}

Se entiende como la evaluación de la etapa de ejecución de la política pública de reconstrucción emprendida por el Estado de Chile en los cerros afectados por el incendio y centrada en la lógica de gestión gerencial, que permitió la participación privada en la prestación de los servicios, a través de empresas constructoras que se adjudicaron la licitación pública, haciéndose cargo del diseño, gestión, administración y reconstrucción de las viviendas siniestradas.

Ahora bien, el primer punto que cabe destacar es la crítica realizada por los maestros de la construcción a la gestión del Estado de Chile en el diseño de la política pública de reconstrucción. Esa crítica gira en torno a la actuación de una tecnocracia hegemónica, que no generó eficientes canales de participación ciudadana, pero que, por sobre todo, mostró una carencia de empatía y falta de escucha de parte de las autoridades en relación a los afectados no estuvieron presentes en las zonas afectadas, no sabían qué necesitaba la población, no tuvieron en cuenta el dolor e impacto a la hora de focalizar mejor la ayuda, y entregar soluciones satisfactorias a las demandas. Es lo que manifiestan las siguientes afirmaciones:

\subsubsection{Ineficiencia de la política pública:}

(...) ellos [el Estado] deberían primero haber estado en terreno, ellos deberían haberse informado, haber preguntado, si aquí no costaba nada haber llegado profesionales más que nada. Yo creo que debería haber llegado el profesional correspondiente, el capacitado para la situación. Aquí llegó mucha gente, seguramente los sacaron de la oficina a inscribir gente y después el gobierno se guio en lo que escribieron, en lo que anotaron. (VP, 15 años de experiencia en construcción).

(...) Uno sabe qué terreno tenía, pero para eso faltó gente: por ejemplo, los topógrafos que llegan a medir los terrenos, los planos. SERVIU tuvo que haberse acercado a los terrenos (...) haber mandado topógrafos a terreno, con los planos, a los dueños de terreno, para que la gente no peleara una con otra (...) (EC, 22 años de experiencia en construcción).

Tal situación ha provocado, según sus afirmaciones, una sensación de desconfianza de los vecinos damnificados hacia las autoridades, debido principalmente a los ineficientes protocolos de catastro y dispositivos de gestión de la información, lo que ha dificultado la gestión en las diferentes etapas de la reconstrucción. Lo antes señalado, queda en evidencia con el siguiente testimonio, que proviene de un damnificado y además maestro de la construcción:

\footnotetext{
[¿Quién ha fallado en la etapa de reconstrucción?] Yo creo que más que nada del municipio. El municipio es el que te traba, el que los sueños te los deja ahí estancados en ideas no más. Es el primer ente al que recurres para poder hacer cosas y son ellos los que te ponen el muro y siempre están ahí, siempre están cerrándote las puertas y tiran los ánimos de todos para abajo. Es esa la organización, que según ellos la tienen al pie de la letra y para nosotros es la contra, porque no es así, no es lo que ellos expresan cuando hablan, cuando los entrevistan y dicen que siempre están ahí, siempre están en terreno. Mentira. Aquí tú no los ves, no ves a ninguna persona del gobierno (...) (VP, 15 años de experiencia en construcción).
}

Pese al reconocimiento de algunos maestros de la construcción sobre el actuar ineficiente por parte del gobierno central y local, otros señalan que una de las consecuencias que han traído los ineficientes protocolos de catastro y dispositivos de información, desde la institucionalidad 
estatal, es la sensación de "aprovechamiento" por parte de algunos damnificados. Esto demuestra una discrecionalidad en la distribución de las soluciones de sus demandas, caracterizada por inoperantes mecanismos de fiscalización y control. Tales afirmaciones quedan refrendadas con los siguientes testimonios -que al igual que el anterior-, han configurado la experiencia de ser, por un lado, damnificados y, por el otro, maestros de la construcción:

(...) no voy a defender al gobierno ni a nada. Sí, el problema es de la gente. La gente causó el problema. La sociedad misma está mal instruida, mal adaptada. Nosotros somos ladrones, queremos acaparar y somos así como localidad (...) (RZ, 25 años de experiencia en construcción).

[Fallas en los protocolos de catastro] Había casos de familias que vivían en una casa. Vivían matrimonios enteros, con hijos, con familias, y después ahora todos los hijos tienen casa. Tú los ves, tienen departamento, tienen casa (...) Si miramos desde el aprovechamiento, aquí ganaron más los que arrendaban, los allegados, ellos ganaron. Fueron a ellos los que les dieron departamentos, subsidios y uno los ve, vivió con ellos, sabía en dónde vivían, cómo vivían, y tú los ves mejor a ellos que a la misma gente que eran dueños de sitios. (VP, 15 años de experiencia en construcción).

[Fallas en la Información del SERVIU, delimitación de los terrenos] Vi mucho aprovechamiento, muchas discusiones, los vecinos discutían unos con otros: "no, que el terreno me corresponde hasta aquí". "No, que te corriste más acá". "No, si me corresponde hasta allá". En fin, cantidad de cosas, muchas cosas que pasaron, muchas cosas que yo vi: vi peleas (...) (EC, 22 años de experiencia en construcción).

Ahora bien, al abordar el desempeño de las empresas constructoras mandatadas por la institucionalidad estatal, se profundizan las críticas por los deficientes dispositivos de fiscalización y control; develando una política pública de reconstrucción, que no ha podido cumplir con los plazos establecidos de entrega de las viviendas. Esto debido principalmente a problemas de administración y gestión, situación que ha ocasionado desconfianza y desesperanza en las familias afectadas en su demanda habitacional.

De lo anterior, al centrarnos en las afirmaciones de los maestros de la construcción, en referencia a las fallas que presentan los dispositivos de fiscalización y control, por parte de la institucionalidad estatal, se hace mención a una consecuencia directa, con la problemática de la administración y gestión de las empresas constructoras. Realidad que se manifiesta en el retraso en la entrega de las viviendas, sumado a las dificultades laborales que presentan los mismos maestros de la construcción. Dificultades dadas esencialmente por su precariedad contractual, en donde no cuentan con contrato, protección social, medidas de seguridad, etc. A continuación, se presentan algunas afirmaciones.

\subsubsection{Incumplimientos de las empresas constructoras}

[Problemas de gestión en la entrega de materiales] Aquí, por lo menos, estamos a la espera de que nos llegue el hormigón para llenar los cimientos, y ya llevamos varios días a la espera y son varios días que nosotros estamos perdiendo plata, porque fuimos contratados para hacer este trabajo por cierta cantidad de dinero, entonces el tema es: ¿cuándo vamos a terminar para poder recibir ese dinero?, y ¿entre más días esperemos es menos plata que estamos ganando? Porque estamos perdiendo dinero, cuando tendríamos que estar en otra obra (...). Pero el tema es que nosotros creemos que pasa solamente por la parte administrativa, porque aquí usted ve, que todas las obras están paradas, los maestros se andan dando vuelta. Aquí ese es el tema, nos encontramos con maestros que están esperando los materiales, que esperan y esperan, y también los otros llaman por teléfono a sus jefes, y no les contestan. No sé, pensarán que uno es una molestia, que más encima uno lo esté llamando por teléfono, y pedimos los materiales y no llegan, y si nos logramos comunicar, nos dicen: "Van a llegar, pero espérate un poquito. Disculpen, pero esperen, esperen". Al final, venimos a traba- 
jar y estamos todo el día sentados sin hacer nada (...) ( $\mathrm{AB}, 27$ años de experiencia en construcción).

[Falta de fiscalización en los precios acordados] Muchas constructoras se han aprovechado y uno lo ve. Ve lo que construyen a lo que están dando y no es realmente lo que debería ser (...) (VP, 15 años de experiencia en construcción).

Las siguientes afirmaciones confirman las demoras en la entrega de las viviendas reconstruidas, lo cual pone de manifiesto nuevamente la falta de fiscalización y control de la institucionalidad estatal a las empresas constructoras, en el cumplimiento de los plazos de entrega de las viviendas:

[Personas que habitan sus casas reconstruidas] Los que yo conozco, del sector que yo manejo el mapa, que es casi todo el mapa del barrio que se quemó, hay un $10 \%$ que está instalado definitivo, y el resto está todo que le falta una cuestión, que le falta otra (...) Hay seis casas que están habitadas en realidad, pensándolo bien están todas las casas paraditas, pero ninguna está habitada. Hay pocas que están habitadas, con el subsidio ya otorgado y ya no hay nada más que hacer, son re pocas. La mayoría está con trámites pendientes, que falta un detalle, que falta el otro, que no la puedo habitar todavía. Hay una que quedó mal hecha y tienen que desarmarla y tienen que hacerla de nuevo, la misma casa, estaba malo el formato, estaba mala desde los cimientos y la norma de reconstrucción no permite reparar (...) (RZ, 25 años de experiencia en construcción).

(...) lo que pasa es que las autoridades no se dan el trabajo de seguir la lógica en este sentido, porque las autoridades deberían estar fiscalizando, que si los trabajadores están haciendo bien su trabajo, si se les está pagando, si tienen precariedad en las herramientas que están utilizando. Y aquí tampoco hay fiscalizadores de seguridad, nada, nada, así no más (...) Les diría que fiscalizaran [autoridades], que fueran donde las papas queman -como se dice vulgarmente, donde está el obrero trabajando en esa casa que está siendo reconstruida, que pregun- ten: ¿qué es lo que le falta para que trabaje bien, para que trabaje con incentivo? Ni siquiera ha venido un día el jefe de la empresa constructora a ver si el trabajo cumple con lo establecido en los planos (...) (AB, 27 años de experiencia en construcción).

En el mismo sentido, los maestros de construcción manifiestan demoras en proporcionar los materiales para terminar sus faenas, por parte de las empresas. Esto ha causado problemas económicos en sus propias vidas familiares, y al mismo tiempo, ha generado un sentimiento de frustración y desesperación de los damnificados, que desean habitar sus viviendas reconstruidas:

[Piensa dejar la reconstrucción de la vivienda] Ojalá que cuando nosotros nos vamos, ojalá que la empresa [constructoras] les corresponda lo que ellos verdaderamente necesitan. Lo lamento mucho, pero yo no le puedo dar respuesta a eso. Sobre lo que va a pasar con ellos, no le puedo dar respuesta, porque son las autoridades. Ellos [damnificados] creyeron que esto iba ser realidad (...) Con ellos tienen que hablar [autoridades] (...) Así que yo me encuentro sumamente achacado, aburrido, de puro pensar, aquí fumando, esperando (...) En mi casa también sufren porque también comen, porque en mi casa también esperan que llegue el hombre con las lucas que se le prometieron por seis días acá de trabajo. Y cuánto llevamos esperando ya, esperando, esperandoY yo no le puedo decir a mi mujer: no pasa nada con la empresa.En la casa uno también sufre por la falta de dineroYo también sufro y ellos [damnificados] sufren más Es su ilusión: les vendieron una ilusión y ellos la compraron (...) (AB, 27 años de experiencia en construcción).

Asimismo, se manifiesta que las empresas constructoras no han aplicado normativas de construcción adecuadas a las características geográficas, tendientes a proteger a las viviendas de los efectos de otro incendio, lo cual puede revelar que la etapa de reconstrucción está privilegiando aspectos de carácter económico en desmedro de la seguridad y la protección de sus habitantes. Tal situación queda en evidencia en las siguientes afirmaciones: 


\begin{abstract}
Al trabajar en un cerro, tienes que estar mucho más consciente de que el construir tiene que ser con mayor responsabilidad.Yo cuando construyo algo lo hago pensando como para mí, pensando que también va a ser mío, porque es la seguridad mía, primero que nada, para que la persona después cuando venga a vivir a una vivienda tenga la seguridad de que no le va a pasar una desgracia. No es lo mismo que una empresa [constructora] (...) Siempre tienes que trabajar bajo las normas de la construcción, de cómo tienes que trabajar. Ahora hay más exigencias, con lo sucedido, así que tienes que ser más minucioso. Cortafuegos, altura, contraterreno, la solidez de la vivienda, esas son normas que son primordiales para poder construir (...) (VP, 15 años de experiencia en construcción).
\end{abstract}

[Construir en cerros] Los muros de contención supuestamente no están contemplados, porque en esto solo se va a hacer el piso de lo que se va a construir. Ahora, el tema, no sé qué le van a colocar a la orilla del cerro, ya que el cerro tiene que tener muro de contención (...) Para contener el agua que viene bajando del cerro: cuando llueve, el agua baja por el terreno del cerro y se le va a meter para adentro de la casa (...) (AB, 27 años de experiencia en construcción).

En definitiva, este primer análisis, centrado en las evaluaciones de los maestros de la construcción en referencia a la relación Estado-Mercado, evidencia que la intervención de la institucionalidad estatal ha procurado mantener los principios de la gobernabilidad dentro de un modelo de capitalismo neoliberal, a pesar que este sistema es incapaz de establecer una formula estable "que concilie las condiciones de gobernabilidad democrática, crecimiento sostenible y distribución equitativa del ingreso, la riqueza y las oportunidades. Bajo estas circunstancias, la agenda estatal se torna cada vez más compleja y contradictoria, a medida que las cuestiones en ella contenidas se vuelven más difíciles de resolver, dadas las expectativas sociales crecientes y los recursos escasos" (Oszlak, 2006, p. 4)

De esta forma, tal complejidad se materializa en la etapa de reconstrucción. Debido principalmente a las ineficiencias en la implementación de la política pública, denotando una baja concientización de la institucionalidad estatal-burocrática.Esto producto de la incongruencia entre la racionalidad técnica y la racionalidad política, trayendo como consecuencia el mantenimiento del status quo en la toma de decisiones, caracterizada por dificultades en los protocolos de catastro y dispositivos de información, que han establecido la desconfianza y la desesperanza de los damnificados. Con lo cual, se mantienen los problemas sociales y las demandas de la ciudadanía damnificada, indicando que la privatización, descentralización, desmonopolización y tercerización de la política pública, ha desdibujado el rol del Estado como generador de integración, inclusión y bienestar social.

Para profundizar en lo anterior, cabe señalar que el proceso de modernización del Estado de Chile, hacia la Nueva Gestión Pública, comienza a finales de los años ochenta, entendida como una reorientación de las políticas administrativas y de gestión hacia una realidad internacional globalizada. Dicha reorientación exigía competitividad en los mercados internacionales para alcanzar una estabilidad política y un desarrollo sustentables en lo económico-social, y así dotar de "mecanismos de democratización y participación ciudadana" (Brunner, 1994; Ahumada, 2006); con el objetivo de alcanzar la igualdad de oportunidades en pos del bienestar social e individual. Sin embargo, se puede establecer que el proceso de reconstrucción no ha sido efectivo, participativo y transparente, y no ha hecho posible involucrar a la sociedad civil en el proceso de toma de decisiones de la política pública, como queda de manifiesto en las afirmaciones de los maestros de la construcción: "las autoridades no están en terreno, no fiscalizan, no han permitido una participación decidida de los damnificados". Esto demuestra que aún se mantienen los mecanismos de exclusión de los sectores marginados y, con ello, la falta de voluntad política para democratizar la toma de decisiones, que impide garantizar los derechos y deberes de la sociedad civil mediante mecanismos de transparencia y control jurídico-administrativo. 


\subsection{Relación habitantes- damnificados}

Se comprendió la evaluación de los maestros de la construcción, sobre sus relaciones sociales establecidas con los habitantes-damnificados, como la constitución de su capacidad para establecer empatía y solidaridad con el otro que sufre.

Ahora bien, las afirmaciones de los maestros de la construcción permiten dividir el análisis de la relación habitantes-damnificados en dos instancias de tiempo: en primer lugar, los días posteriores al incendio y, en segundo lugar, la etapa de reconstrucción. Tal división, nos permite observar cómo la hegemonía del poder político-económico produce cambios en los discursos tendientes a la individuación de sus intereses, reflejando una fragmentación entre las acciones que buscan el bienestar de la sociedad en su conjunto y el interés por la satisfacción individual.

\subsubsection{Días posteriores al incendio}

Al centranos en los días posteriores al incendio, las afirmaciones apuntan a mecanismos de solidaridad y empatía con los damnificados, materializados en acciones espontáneas de ayuda, y generosidad material y emocional. Tal situación, queda evidenciada en las siguientes aseveraciones de dos maestros de la construcción, que también fueron damnificados por el incendio:

[Voluntarios] bastante ayudaron. Los universitarios. Harta gente me ayudó. Yo tuve harta gente, hartos universitarios que venían de lejos y ahí me decían: "caballero, ya, ¿le ayudamos?”. Y yo les decía: “Bueno, ya". Me ayudaban. 15 personas ayudando a limpiar el terreno (...) (EC, 22 años de experiencia en construcción).

[Voluntarios] aquí fueron parte primordial del desarrollo del sector, del ánimo, de sacarnos del dolor, de la angustia, de la pena, de miles de cosas que estaban pasando en ese momento. Son ellos los que están dán- dote el aliento de que tú puedes (...) (VP, 15 años de experiencia en construcción).

Cabe destacar que unánimemente, en las afirmaciones, se hace referencia a que la sociedad en general demostró más "humanidad".

\begin{abstract}
(...) fue más humano, fue más humano, nosotros lo vivimos. Vimos gente que venía en ayuda de la gente, vimos cómo llegaban empresas de materiales, cómo regalaban cosas para que la gente [damnificados] empezara sola a reconstruir. Hay muchas casas que se han reconstruido porque la misma gente, los dueños de casa, lo han hecho y lo han hecho con puras cosas que les han regalado, puras donaciones... (AB, 27 años de experiencia en construcción).
\end{abstract}

[Efectos del Incendio] socialmente hablando sí fue el remezón, el tirón de mechas de esa gente que no saluda al vecino, que no conversa con el del frente, esa que cree que "ustedes son distintos a mí". No, ahí se dieron cuenta de que somos todos iguales (...) (RZ, 25 años de experiencia en construcción).

De esta forma, al analizar la relación habitantes-damnificados, se observa en las afirmaciones de los maestros de la construcción que la intensidad de la ayuda y el voluntarismo de la sociedad, en general, ha bajado. Esto ha dado paso, de alguna forma, a la naturalización del sufrimiento de los damnificados y el reposicionamiento de los intereses individuales, manifestándose en el siguiente punto.

\subsubsection{Etapa de Reconstrucción:}

(...) yo creo que ha pasado más de un año que pasó esa ayuda como humanitaria y la gente tiene que volver a su ritmo de vida, tiene que seguir su camino de desarrollo (...) ya no está esa ayuda de cuando venían antes y no sé, te ayudaban a limpiar, a levantar una casa, una mediagua (...) yo me acuerdo de los comedores comunitarios donde la gente venía con gusto a almorzar, la gente de afuera venía y la preparaba, también venía con un entusiasmo súper alentador, súper digno de las personas, que 
sabiendo que de su bolsillo salía algo súper lindo (...) (VP, 15 años de experiencia en construcción).

[La ayuda a los Damnificados] ya se perdió, porque ya pasó el incendio, ya no se siente el olor a humo, entonces nadie ayuda a nadie. Ahora la gente que está desprotegida tiene que ver por las suyas no más, nada más. Eso es lo que nosotros vemos aquí. Hay mucha gente que está reconstruyendo sus mediaguas, usted ve, hay unas casas bien bonitas y otras que son bien pobres. Como se podría decir en términos nuestros, bien rascas, por decir bien precarias (...) (AB, 27 años de experiencia en construcción).

Cabe destacar que, a pesar de la catástrofe que significó el incendio entre los habitantes-damnificados -y que no se cuente con la misma ayuda material y emocional- según las afirmaciones de los maestros de la construcción, los lazos sociales entre vecinos se han fortalecido mediante la conformación de organizaciones sociales, que buscan enfrentar juntos los problemas de seguridad y limpieza de su entorno. Además, diseñar planes preventivos y de contingencia que eviten, de alguna manera, el surgimiento de nuevos incendios. Tal realidad queda de manifiesto en las afirmaciones de dos maestros de la construcción que fueron afectados:

(...) junta de vecinos no teníamos nosotros, ahora ya tenemos junta de vecinos y hay que tratar de, no sé, tener unas mangueras de alta presión y tener más control con los fuegos (...) poner más grifos, estar más preparados (...) (EC, 22 años de experiencia en construcción).

(...) nosotros acá, del hecho de vivir muchos años, nunca tuvimos una junta de vecinos, eso nos ha ayuda do mucho a unirnos. Ahora tenemos una junta de vecinos en la cual nosotros hacemos actividades y ahí empezamos a conocer al vecino (...) ibas viendo lo más personal de cada uno y eso mismo nos ayudó al diálogo, a unirnos como vecinos y a comunicarnos, a estar más preparados (...) ahora nos ayudamos y nos apoyamos de una forma más familiar (...) (VP, 15 años de experiencia en construcción).
En síntesis, se aprecia -en las afirmaciones de los maestros de la construcción- que la hegemonía de la institucionalidad política-económica impone al sujeto un cálculo racional para la realización de sus medios-fines, instaurando un tipo de dominación que representa la asociación entre el poder y su legitimidad, que afecta directamente su autonomía, mediante relaciones sociales, políticas, económicas y culturales, dentro de los parámetros economicistas, configurando un egoísmo de mercado que invisibiliza los intereses y el bien común de una sociedad. No obstante lo anterior, tragedias como el incendio de Valparaíso permiten instancias de reorganización de lo social, en donde existe "la posibilidad" manifiesta de la configuración de una resistencia y la "reparación del daño" de los sujetos subalternos, ya que justifican la emergencia de procesos de subjetivación política, a través de las organizaciones sociales y la participación en espacios públicos, evitando la individuación acrítica del consumismo y la desidentificación con las desigualdades sociales impuestas por la hegemonía político-económica.

\section{Reflexión sobre los alcances y limitaciones de los mecanismos de solidaridad con el otro que sufre}

$\mathrm{Al}$ realizar esta reflexión desde las afirmaciones de los maestros de la construcción, se reflejan las interacciones sociales, las cuales se conformaron desde el interés por cooperar, con el objetivo de recomponer o restaurar el desarrollo de las vidas cotidianas de los damnificados. Así entonces, la solidaridad se manifiesta desde una interdependencia de un grupo social que establece una retribución horizontal de acciones y motivaciones, para alcanzar el bienestar y el bien común de toda su comunidad.

En este sentido, consideramos relevante para esta reflexión incorporar la perspectiva de los damnificados por el incendio, además de algunos razonamientos surgidos en catorce meses de observación etnográfica en la zona afectada.

De esta forma, las afirmaciones tanto de los vecinos damnificados como de los maestros de la 
construcción abordan los mecanismos de solidaridad desde dos aspectos fundamentales: en primer lugar, la colaboración humanitaria, compuesta esencialmente por agrupaciones de estudiantes, de profesionales, empresas, amigos y familiares, los cuales colaboraron en la remoción de escombros, limpieza de terrenos, donaciones de enseres, vestimentas y alimentos, etc. Esta instancia es recordada como la materialización de acciones y discursos que dotaron de esperanza y fuerza.

En contraposición, el segundo aspecto recurrente en sus afirmaciones, son las conductas delincuenciales posteriores al incendio, como también la reprochable utilización y defraudación de la colaboración recibida, por parte de algunos vecinos. Situación que describen como la principal limitación de los mecanismos de solidaridad y definen como "aprovechamiento".

\subsection{Colaboración humanitaria}

Cuando definimos colaboración humanitaria, lo hacemos centrando la mirada desde los significados de equidad, conformados esencialmente por la preocupación fraternal del bienestar del otro que sufre, en la cual se activan dispositivos colectivos para aliviar y/o superar la tragedia y alcanzar la normalización de las vidas cotidianas de este, enmarcados en voluntad y genuina justicia social.

\footnotetext{
Nosotros veíamos cómo llegaba la gente acá con camionetas, con cosas para la gente [damnificados] con ropa, con enceres y se vivió algo humanitario muy positivo (...) (AB, 27 años de experiencia en construcción).
}

[Colaboración con los vecinos en el momento del incendio] yo arriesgué mi salud, arriesgué muchas cosas, mis hijas. Yo sentí hacerlo y eso a mí me llena. Si yo veo que puedo ayudar a una persona y está bien, quedo contenta con lo que yo la pude ayudar. Yo con eso me doy por pagada, no espero algo a cambio (...) (MC, vecina de los cerros siniestrados).

(...) llegó harto apoyo psicológico, llegó harto psicólogo, llegó ayuda. O sea, yo no tengo nada que decir en cuanto a la ayuda

\begin{abstract}
humana, vinieron muchas agrupaciones, muchas personas con una actitud altruista a ayudarte (...) (RM, vecino de los cerros siniestrados).

(...) me venían a ver y a dejarme cosas [equipo de rugby], pero yo se las dejaba a los vecinos porque nosotros no tuvimos grandes problemas (...) (AS, vecina de los cerros siniestrados).
\end{abstract}

Así entonces, podemos apreciar que la solidaridad como colaboración humanitaria, se basa principalmente en una cohesión social que constituye una fraternidad con el otro que sufre, conformando una comunidad de la interdependencia y el cuidado recíproco, desde significaciones esencialmente altruistas. Desde Durkheim (2004), podemos afirmar la existencia de una solidaridad orgánica, que se caracteriza por un desarrollo recíproco, entre la consciencia colectiva y la consciencia individual, para alcanzar el bien común.

\subsection{Aprovechamiento social}

$\mathrm{Al}$ abocarnos a definir el aprovechamiento social ocurrido en el momento mismo y con posterioridad al incendio, sumado también, al despliegue solidario realizado por la sociedad en su conjunto en los cerros siniestrados, lo debemos hacer desde las acciones que atentan en contra de la colaboración humanitaria. Acciones dadas por una vulneración de la esencia valórico-moral, caracterizadas por una desconexión con el otro que sufre y por buscar solo el beneficio individual, evadiendo la responsabilidad, la reciprocidad y la generosidad que exige la acción fraterna para alcanzar el bienestar de toda la comunidad.

[Honorarios después del Incendio] había gente que decía: [Maestros de la construcción] "no, yo no valgo 15 lucas ahora" "¿Y cuánto vales ahora?" "Ahora valgo 25 lucas [dinero]". Yo no, porque siempre mantuve el mismo precio (...) (EC, 22 años de experiencia en construcción).

(...) esa es otra historia: el aprovechamiento social que hubo. Aparecieron vecinos que nunca fueron vecinos del cerro, casas que 
no existían de pronto aparecieron. Sectores que no tenían casas pero que, al momento de llegar las mediaguas, se formaron poblaciones en ellos. ¿De dónde salieron esas casas? Cuando se entregaron los subsidios mucha gente se aprovechó también. ¿Por qué lo digo? En nuestro caso eran dos casas y yo de allegado, tres familias prácticamente, pero nos dieron dos subsidios. Sin embargo, yo no quise postular porque consideré que no era la forma de aprovecharse, a todos nos tocó, no debía tomar esa opción que no me parecía. Luego con el tiempo, sabiendo lo que ocurrió, puta que fui weón. ¿Por qué no me aproveché? Pero mi consciencia está tranquila, ya que no me parece que fuera la forma de hacerlo (...) (GV, vecino de los cerros siniestrados).

(...) gente que nunca había visto en mi vida andaba en este cerro robando cosas cuando estábamos evacuando, la gente es muy mala (...) (MS, vecino de los cerros siniestrados).

(...) hay mucha gente [damnificados] que todavía tiene mediaguas [casas prefabricadas], porque las empresas [constructoras] las dejaron botadas [sin la reconstrucción de sus casas]. Quedó botada la gente (...) ( $\mathrm{MM}$, vecina de los cerros siniestrados).

A modo de cierre de este apartado, podemos afirmar que, a pesar del "aprovechamiento social", los mecanismos de solidaridad en los cerros siniestrados demuestran la configuración de acciones generosas hacia el otro que sufre. Manifestando que en escenarios catastróficos se unen en una hermandad, que resalta y revitaliza el respeto mutuo, la reciprocidad y de sobremanera el sentido de la interdependencia y la responsabilidad con la comunidad, además del fortalecimiento de la pertenencia al espacio social, en donde se construye la identidad individual y el compromiso moral con el otro.

\section{Conclusiones}

$\mathrm{Al}$ escuchar e interpretar al maestro de la construcción, en su posición de sujeto subalterno, debemos concluir que materializa una resistencia a la dominación política y económica desde una solidaridad hacia el otro que sufre, fundamentada en una crítica a la indeficiente política pública de reconstrucción de viviendas implementada por la hegemonía del Estado de Chile. Para ello, ejerce un reconocimiento de agencia, basado en una consciencia de clase constituida en una subjetivación política, que exige una reconversión social, tendiente a garantizar el bienestar y la igualdad de derechos para él y para quienes sufren.

En definitiva, podemos afirmar que, en la relación Estado-Mercado, los maestros de la construcción basan su crítica en una tecnocracia hegemónica que no ha garantizado los mecanismos de integración y reinserción social de los damnificados por el incendio. Realidad que les niega la posibilidad de alcanzar la reparación de daños -mediante la participación en la toma de decisiones- y en donde se obstaculizan los mecanismos de comunicación para la constitución de una política pública de reconstrucción, focalizada de sus demandas. Esto devela la carencia de empatía y solidaridad con el otro que sufre, por parte de la institucionalidad estatal.

Por otro lado, al referirnos a la relación Habitantes-Damnificados, debemos precisar que, desde las afirmaciones de los maestros de la construcción, se establece una incipiente resistencia a los procesos de individuación mediante mecanismos de interrelación e interdependencia de sus comunidades, que operan solidariamente y de forma independiente a la institucionalidad estatal. Lo cual demostraría una desidentificación de las desigualdades sociales impuestas por la hegemonía del poder político-económico, con la finalidad de exigir bienestar e igualdad social.

Finalmente, concluimos que los mecanismos de solidaridad desde la perspectiva de la colaboración humanitaria, se configuran como resistencia a la hegemonía política-económica, basada en una consciencia individual y colectiva. Consciencia tendiente a la responsabilidad, la reciprocidad y la generosidad, con la finalidad de conseguir el bienestar y el bien común de la comunidad en su conjunto. 
Maestros de la construcción. Protagonistas subalternos del proceso de reconstrucción de los cerros de Valparaíso en Chile

\section{Referencias}

Ahumada, J. (2006). Modernización del Estado de Chile (tesis de maestría). Escuela de Gobierno y Gestión Pública, Universidad Academia de Humanismo Cristiano, Santiago, Chile.

Angelcos, N. (2008). Subjetividad y política: sobre el rendimiento sociológico de los procesos de subjetivación. Santiago, Chile: Departamento de Sociología, Facultad de Ciencias Sociales, Universidad de Chile.

Briones, G. (1999). Métodos y Técnicas de Investigación para las Ciencias Sociales. Ciudad de México, México: Trillas.

Brunner, J. (1994). Bienvenidos a la modernidad. Santiago, Chile: Planeta.

Delleuze, J. (1998). La Policía de las Familias. Valencia, España: Pre-textos.

Sousa-Santos, B. (2010). Descolonizar el Saber, Reinventar el Poder. Montevideo, Uruguay: TRILCE.

Delleuze, G y Guattari, F. (1972). El anti-Edipo. Capitalismo y esquizofrenia. París, Francia: Miniut.

Durkheim, E. (2004). La división del trabajo social. Buenos Aires, Argentina: Libertador.

Foucault, M. (1977). Language, Counter-Memory, Practice: Selected essays and interviews. Ithaca, US: Cornell University Press.

García, N. (1989). Culturas híbridas. Estrategias para Entrar y Salir de la Modernidad. Ciudad de México, México: Grijalbo.

Glissant, E. (1989). Carribbean Discourse. Selected Essays. Charlottsville, US: Virginia University Press.

Gramsci, A. (1981). Cuadernos de cárcel Volumen I (1930). Ciudad de México, México: ERA.

Greenblatt, S. (1992). Marvelous Possessions. The Wonder of the New World. Chicago, US: Chicago University Press.

Guattari, F. (1973). Para terminar con la Masacre del Cuerpo. Recherches, (12), s.p.

Guha, R. y Spivak, G. (1988). Selected Subaltern Studies. New York, US: Oxford University Press.

Guha, R. (1996). The Small Voice of History. En R. Guha y G. Spivak (Eds.), Subaltern Studies I, Subaltern Studies II, Elementary Aspects of Peasant Insurgency in Colonial India, y Subaltern Studies IX (pp. 38-89). New Delhi/Bombay/Calcutta, India: Oxford University Press.

Horkheimer, M. (2002). Teoría tradicional y teoría crítica. Barcelona, España: Paidós.

Hume, P. (1986). Colonial Encounters. Europe and the Native Caribbean 1492-1797. London, UK: Routledge.

Lukács, G. (1970). Historia y Conciencia de Clase. Ciudad de México, México: Grijalbo.

Martínez M. (2002). La Investigación Cualitativa Etnográfica en Educación. Ciudad de México, México: Trillas.

Mignolo, W. (1995). The Darker Side of the Renaissance. Literacy, Territoriality and Colonization. Ann Arbor. Michigan, US: Michigan University Press. 
Ministerio del Interior y Seguridad Pública. (2014). Informe Reconstrucción Valparaíso: Plan de Inversiones, Reconstrucción y Rehabilitación Urbana. Valparaíso 2014-2021. Santiago, Chile: Comisión Interministerial Ciudad, Vivienda y Territorio, Gobierno de Chile.

OIT -Organización Internacional del Trabajo-. (2003). Actividades normativas de la OIT en el ámbito de la seguridad y la salud en el trabajo: estudio detallado para la discusión con miras a la elaboración de un plan de acción sobre dichas actividades. Conferencia Internacional del Trabajo 9lva reunión. Informe VI. Ginebra, Suiza: OIT.

Oszlak, O. (2006). Burocracia Estatal: Política y Políticas Públicas. POSTData Revista de Reflexión y Análisis Político, (11), 1-30.

Spivak, G. (1988). ¿Puede hablar el sujeto subalterno? Memoria Académica, 3(6), 175-235. Recuperado de http://www.memoria.fahce.unlp.edu.ar/art_revistas/pr.2732/pr.2732.pdf/

Szurmuk, M. y Mckee R. (2009). Diccionario de Estudios Culturales Latinoamericanos. Ciudad de México, México: Siglo XXI.

Valles, M. (1993). Técnicas de Investigación Social: Reflexión Metodológica y Práctica Profesional. Madrid, España: Síntesis.

Weber, M. (2004). Economía y Sociedad: Esbozo de Sociología Comprensiva. Ciudad de México, México: Fondo de Cultura Económica. 